\title{
DIAGNÓSTICO SITUACIONAL DA ADESÃO ÀS BOAS PRÁTICAS HIGIÊNICAS EM SUPERMERCADOS DE UM MUNICÍPIO DA REGIÃO METROPOLITANA DE CURITIBA-PR, BRASIL
}

\author{
(Situacional diagnosis of good hygiene practices adequacy in supermarkets in a \\ metropolitan region of Curitiba, Parana, Brazil)
}

\author{
Danieli Muchalak dos Santos ${ }^{1 *}$, Marcia Oliveira Lopes ${ }^{1}$, Caroline Constantino ${ }^{1}$, Vivien Midor \\ Morikawa $^{1}$, Luana Costa Lima Hildebrando², Jairo Fernandes de Queiroz ${ }^{2}$

\footnotetext{
${ }^{1}$ Universidade Federal do Paraná, Brazil. *Corresponding author: danieli muchalak@yahoo.com.br

${ }^{2}$ Secretaria Municipal de Saúde de Piraquara, Paraná, Brazil
}

RESUMO: Supermercados configuram o principal local de aquisição de alimentos pela população. A baixa adesão às Boas Práticas higiênicas em tais estabelecimentos pode comprometer a oferta de alimentos inócuos. Objetivando-se identificar a adequação às Boas Práticas em supermercados de um município da região metropolitana de Curitiba, realizou-se um estudo exploratório-descritivo em 19 supermercados por meio da aplicação de um checklist. Os estabelecimentos foram classificados em grupos, segundo o percentual de conformidade às Boas Práticas, dado que: 10,53\% ( $n=2)$ alcançaram classificação 1 (entre 76 a 100\% de conformidade); $15,79 \%(n=3)$ atingiram classificação 2 (entre 51 a $75 \%$ de conformidade) e 73,68\% ( $n=14)$ apresentaram classificação 3 (conformidade com a legislação sanitária inferior a 50\%). Constatou-se alto índice de irregularidades em áreas que não são visíveis ao consumidor, como nas câmaras frias de produtos cárneos refrigerados que apresentaram produtos em contato direto com o piso em $47,37 \%(n=9)$ dos casos. Observou-se risco de contaminação cruzada em $57,89 \%$ $(n=11)$ dos balcões refrigerados; $52,63 \%(n=10)$ das câmaras frias de produtos cárneos refrigerados; e $31,58 \%(n=6)$ das câmaras frias de produtos cárneos congelados. Notou-se a utilização de alimentos vencidos em $36,84 \%(n=7)$ das padarias. Quanto à higiene pessoal dos manipuladores, verificou-se que $84,21 \%$ $(n=16)$ dos sanitários não apresentavam pia com sabonete líquido e papel toalha para a adequada higienização das mãos. A presença ou vestígios de pragas foi constatada em $63,16 \%(n=12)$ dos casos. Dessa forma, o panorama sanitário identificado demonstrou ausência de conformidade em áreas críticas para segurança alimentar, caracterizando risco à saúde do consumidor.

Palavras-chave: Doenças Transmitidas por Alimentos; higiene dos alimentos; manipulação de alimentos; segurança alimentar

ABSTRACT: Supermarkets are the main source of food acquisition of population. The low adequacy of sanitary good practices in these facilities may jeopardize the offer of innocuous groceries. Aiming at identifying adequacy to good practices in supermarkets from a Curitiba-metropolitan-region city an exploratory-descriptive study was done in 19 supermarkets through a checklist. The commercial establishments were classified into groups according to the percentage of compliance with good practices, meaning: $10.53 \%(n=2)$ reached classification 1 (between 76 and $100 \%$ of compliance); $15.79 \%(n=3)$ hit classification 2 (between 51 and $75 \%$ of compliance); and $73.68 \%(n=4)$ showed classification 3 (with sanitary legislation conformance percentage below 50\%). A high level of irregularities was noticed in areas which are not visible to consumers, such as the refrigerated 
chambers of meat-based cooled products which presented a direct contact with the floor in $47.37 \%(n=9)$ of the cases. The risk of crossed contamination was found in $57.89 \%(n=11)$ of refrigerated containers; $52.63 \% \quad(n=10)$ of the refrigerated chambers of meat-based cooled products; and $31.58 \%(n=6)$ of the refrigerated chambers of frozen meat-based products. It was detected the usage of out-of-date food in $36.84 \%(n=7)$ of bakeries. Regarding the personal hygiene of the handlers, it was noticed that $84.21 \%(n=16)$ of toilets did not present a sink with liquid soap nor paper towels for proper hand hygiene. The presence or traces of plagues was found in $63.16 \%(n=12)$ of the cases. Therefore, the identified sanitary overview showed lack of conformance in critical areas for food security, which characterizes a harmful to consumers health.

Keywords: Foodborne diseases; food hygiene; food manipulation; food safety

\section{INTRODUÇÃO}

Os alimentos são uma necessidade diária de todo ser humano e uma grande responsabilidade para quem os comercializa. Para que um alimento seja considerado seguro deve apresentar aspectos sensoriais desejáveis e, do ponto de vista sanitário, ausência ou tolerância de microrganismos patogênicos e ausência de riscos físicos e químicos (Gomes, 2007; Meireles, 2015).

As Doenças Transmitidas por Alimentos (DTA) afetam a saúde de milhões de pessoas devido ao consumo de alimentos que não são inócuos. Tais enfermidades contribuem para 0 agravamento dos níveis de insegurança alimentar e tornando-se relevantes no perfil de morbimortalidade da população brasileira, em especial em grupos de risco - crianças, idosos, gestantes e pessoas imunodeprimidas (Ramos, 2014).

A ocorrência destas moléstias se deve geralmente a falhas na manipulação dos alimentos e, menos frequentemente, à contaminação destes alimentos em sua origem (OMS, 2018). Segundo a Organização Mundial de Saúde, mais de $60 \%$ dos casos de doenças de origem alimentar decorrem do descuido higiênico-sanitário de manipuladores, das técnicas inadequadas de processamento e da deficiência de higiene da estrutura física, utensílios e equipamentos (WHO, 2017).

De acordo com a Resolução RDC no216/2004, da Agência Nacional de Vigilância Sanitária (ANVISA), que dispõe sobre o Regulamento Técnico de Boas Práticas para Serviços de Alimentação, as Boas Práticas de fabricação e manipulação de alimentos são o "conjunto de procedimentos que devem ser adotados por serviços de alimentação a fim de garantir a qualidade higiênico-sanitária e a conformidade dos alimentos com a legislação sanitária vigente". Portanto, as Boas Práticas formam um conjunto de princípios e regras para o correto manuseio dos alimentos, abrangendo desde matérias-primas até o produto final, de forma a garantir a segurança e a integridade da saúde do consumidor. A avaliação de tais práticas em conjunto com a análise do potencial de riscos são os aspectos que regem as inspeções da Vigilância Sanitária de alimentos.

Nesse contexto, os supermercados são locais relevantes para ações preventivas sobre as DTA por configurarem 0 principal meio de aquisição de alimentos e um dos mais complexos, no qual coexistem diferentes gêneros alimentícios, distribuídos em diversos setores - padaria, confeitaria, açougue, salsicharia, alimentos secos, 
produtos de autosserviço, frios, produtos prontos para o consumo, dentre outros (Soto et al., 2006; Azevedo, 2017). À vista disso, a necessidade de adequação às Boas Práticas higiênicas torna-se fundamental em tais estabelecimentos.

Os supermercados, apesar de representarem um setor significativo da economia brasileira, ainda são pouco estudados, principalmente quanto aos aspectos higiênico-sanitários. A falta de dados do setor supermercadista com relação às questões envolvendo a qualidade dos alimentos no Brasil, muitas vezes, impossibilita o desenvolvimento de estudos mais detalhados na área de segurança dos alimentos (Brasil, 2011). Dessa forma, o objetivo deste trabalho foi avaliar a adesão às Boas Práticas higiênicas em supermercados de um município da região metropolitana de Curitiba e, consequentemente, fornecer subsídios aos serviços de vigilância em saúde para 0 desenvolvimento de ações educativas.

\section{MATERIAL E MÉTODOS}

Como critério de inclusão da pesquisa foram selecionados estabelecimentos com base na definição de supermercado presente na Classificação Nacional de Atividades Econômicas (CNAE, 2007) - comércio varejista de mercadorias em geral, com predominância de produtos alimentícios e área de venda entre 300 e $5000 \mathrm{~m}^{2}$, totalizando um universo de 21 estabelecimentos no município. A pesquisa foi autorizada mediante assinatura de um termo de adesão e comprometimento, sendo que 19 supermercados firmaram participação.

Para avaliar a adequação dos estabelecimentos às boas práticas higiênicas foi elaborada, validada e aplicada uma lista de verificação baseada na RDC no 216/2004 da
ANVISA (BRASIL, 2004) contemplando 20 áreas do setor supermercadista: área externa (frente e fundos), área de vendas, sanitários destinados ao público, sanitários e vestiários destinados aos funcionários, câmara fria de produtos cárneos refrigerados, câmara fria de produtos cárneos congelados, câmara fria de demais produtos refrigerados, açougue, salsicharia/fiambreria, cozinha, padaria/rotisseria, ilhas/balcões, área de recebimento, estoque seco, manipuladores, controle da qualidade da água, controle integrado de vetores e pragas urbanas, documentação e gerenciamento de resíduos sólidos; totalizando 376 itens em perquirição. Ademais, realizou-se o mapeamento fotográfico ambiental para o estudo das não conformidades, bem como para orientar os manipuladores e gerentes em futuras oficinas de capacitação.

Quanto à comparação das frequências relativas de conformidades por área do setor supermercadista, foram somados o número de itens conformes assim como o número de itens não conformes e comparados ao número total de itens avaliados por área.

As visitas aos supermercados foram realizadas no período de fevereiro a junho de 2017 e os resultados obtidos foram tabulados e analisados utilizando o programa Microsoft Office Excel 2013.

Para a classificação dos estabelecimentos, os mesmos foram relacionados em grupos segundo apresentação de conformidades com a legislação sanitária vigente, baseandose na classificação presente na RDC no 275/2002 da ANVISA, sendo classificados no Grupo 1 os supermercados que apresentaram 76 a $100 \%$ de conformidade, no Grupo 2 os que apresentaram 51 a $75 \%$ e no Grupo 3 os que apresentaram percentual de conformidade inferior a $50 \%$. 


\section{RESULTADOS E DISCUSSÃO}

A distribuição

dos estabelecimentos em grupos evidenciou que apenas $10,53 \%(n=2)$ alcançaram classificação $1 ; 15,79 \%(n=3)$ atingiram classificação $\quad 2 ;$ e $\quad 73,68 \% \quad(n=14)$ apresentaram classificação 3 , com percentual de conformidade com a legislação sanitária inferior a 50\% (BRASIL, 2002). A ANVISA recomenda que, para minimizar os riscos de DTA, os atributos avaliados obtenham percentuais de conformidade maiores que $76 \%$, ou seja, enquadrem-se no Grupo 1 (BRASIL, 2002). Sendo assim, o grau de atendimento às Boas Práticas na maior parte dos estabelecimentos analisados estava abaixo do preconizado pela ANVISA, caracterizando risco à saúde do consumidor.

Costa et al. (2013) encontrou resultados semelhantes ao analisar as condições higiênico sanitárias e físico estruturais da área de manipulação de carne in natura em minimercados de Recife (PE). Tais autores observaram que, dos 21 minimercados avaliados, nenhum $(\mathrm{n}=0)$ enquadrou-se no Grupo $1 ; 19,05 \%(n=4)$ foram classificados no Grupo 2; e, o maior número de estabelecimentos, $80,95 \% \quad(n=17)$, apresentou-se no Grupo 3, obtendo baixa adequação.

Também foram comparados os níveis de conformidade por área do setor supermercadista (Figura 01). Ressalta-se que nem todos os estabelecimentos apresentavam todas as áreas avaliadas, dessa maneira, 0 universo amostral por área foi variável, impedindo a comparação entre frequências absolutas. Constatou-se alto índice de irregularidades em áreas que não são visíveis ao consumidor, como: documentação e registros $(80,53 \%)$, área externa dos fundos $(76,92 \%)$, área de recebimento de mercadorias $(76,84 \%)$, gerenciamento de resíduos sólidos $(73,87 \%)$, estoque seco $(70,69 \%)$, sanitários e vestiários destinados aos funcionários $(64,56 \%)$ e controle integrado de vetores e pragas urbanas (50\%). Estes dados revelam que áreas não visíveis ao consumidor têm recebido menor implementação das Boas Práticas, colocando em risco a oferta de alimentos seguros.

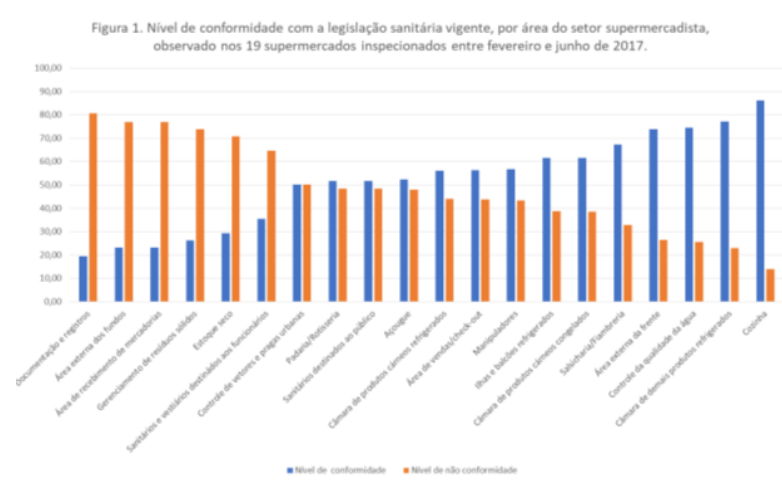

Observou-se que $36,84 \% \quad(n=7)$ dos estabelecimentos não mantinham as instalações e os móveis da área de vendas em condições higiênicosanitárias apropriadas e que 78,95\% $(n=15)$ apresentavam produtos expostos à venda em contato direto com o piso, deixando os alimentos suscetíveis à contaminação.

Em relação aos sanitários e vestiários, verificou-se a ausência de pia com sabonete líquido, produto antisséptico e papel toalha em $84,21 \%$ $(n=16)$ dos sanitários destinados aos funcionários e $31,58 \% \quad(n=6)$ dos sanitários destinados ao público, impedindo a adequada higienização das mãos de clientes e manipuladores de alimentos. As mãos constituem importante fonte de microrganismos e, quando não higienizadas adequadamente, podem servir como veículo para a contaminação dos alimentos manipulados (Forsythe, 2013).

Além disso, $47,37 \% \quad(n=9)$ dos sanitários dos funcionários 
apresentavam comunicação direta com áreas de preparação e/ou armazenamento de alimentos, facilitando a dispersão de patógenos.

Estes resultados discordam dos resultados obtidos em pesquisa realizada por Costa et al. (2013), na qual foi possível notar que apenas $4,76 \%(n=1)$ dos 21 sanitários avaliados em minimercados de Recife (PE) apresentava comunicação com a área de manipulação de alimentos e estava ausente dos itens necessários para a higienização das mãos. Conforme a RDC no 216/2004 da ANVISA, as instalações sanitárias e os vestiários não devem ter comunicação com a área de manipulação e armazenamento dos alimentos e devem apresentar pias supridas de sabonete líquido inodoro, produto antisséptico e toalhas de papel não reciclado ou outro sistema higiênico e seguro para secagem das mãos (BRASIL, 2004).

Ao avaliar as câmaras frias de produtos cárneos, contatou-se que $47,37 \% \quad(n=9)$ das câmaras de resfriados e $21,05 \%(n=4)$ das câmaras de congelados possuíam produtos cárneos em contato direto com o piso, caracterizando risco de contaminação dos mesmos. Da mesma forma, os produtos estavam em contato direto com as paredes em 63,16\% $(n=12)$ das câmaras de resfriados e $42,11 \% \quad(n=8)$ das câmaras de congelados.

No que se refere à contaminação cruzada pelo contato direto de produtos cárneos crus e produtos prontos para 0 consumo, verificou-se 0 risco de contaminação cruzada em 52,63\% $(n=10)$ e $31,58 \% \quad(n=6)$ das câmaras frias de produtos cárneos resfriados e congelados, respectivamente, e em $57,89 \%(n=11)$ dos balcões refrigerados dos açougues, sendo possível observar o armazenamento de peixe e peças de carne bovina/suína juntamente com peças de queijos e leite.
A contaminação cruzada com microrganismos patogênicos caracteriza grande desafio para a saúde pública, especialmente quando ocorre em alimentos prontos para o consumo, os quais não passarão por processo térmico para que se possa eliminar e/ou reduzir a carga microbiana patogênica (Faria, 2016). O Codex Alimentarius (2017) descreve a necessidade de medidas que impossibilitem a ocorrência de contaminação cruzada, considerada uma das principais causas de surtos de doenças de origem alimentar.

Resultados obtidos em uma pesquisa realizada por Mello et al. (2013) em Unidades de Alimentação e Nutrição (UANs) de Porto Alegre (RS) também revelaram episódios passíveis de transferência de microrganismos de alimentos crus para alimentos prontos para o consumo, como o armazenamento de sobremesas sob cubas com carne crua.

Ademais, nos dezenove supermercados avaliados foi possível observar a comercialização de alimentos em embalagens danificadas e/ou com sujidades que poderiam alterar a qualidade e integridade dos produtos cárneos em $42,11 \%(n=8)$ dos açougues. Para a garantia de qualidade dos produtos expostos ao consumidor as embalagens primárias das matériasprimas e dos ingredientes devem estar íntegras (Vidal, et al., 2011). De acordo com Silva Jr. (2005), as matérias primas, ingredientes e embalagens precisam estar em condições higiênicosanitárias adequadas, evitando-se o contato direto entre alimentos crus, semiprontos e prontos para o consumo.

No que se refere aos produtos destinados à devolução ou descarte, a ANVISA (BRASIL, 2004) estabelece que estes devem ser identificados para tal fim e armazenados separadamente dos demais, entretanto os estabelecimentos apresentavam estes produtos não identificados e misturados aos demais 
em $63,16 \%(n=12)$ das câmaras frias de produtos cárneos refrigerados e em $57,89 \%(n=11)$ dos estoques secos, gerando risco de comercialização e/ou reutilização de produtos impróprios para o consumo. Aliando-se a isso, foi possível visualizar em $36,84 \%(n=7)$ dos estabelecimentos a reutilização de alimentos vencidos nas formulações das padarias.

Em relação à periodicidade inadequada dos procedimentos de higienização das instalações, dos equipamentos e dos móveis, observouse falta de higiene em $73,68 \% \quad(n=14)$ dos estoques secos; $57,89 \%(n=11)$ das câmaras frias de produtos cárneos refrigerados; $47,37 \% \quad(n=9) \quad$ dos açougues; $36,84 \% \quad(n=7) \quad$ das padarias/rotisserias; e 31,58\% ( $n=6)$ das câmaras frias de produtos cárneos congelados. Ademais, aliando-se ao precário estado de higiene observado nas câmaras frias refrigeradas atentouse para o fato de $63,16 \%(n=12)$ destas apresentarem pisos, paredes e tetos mal conservados, com rachaduras, trincas, goteiras, bolores e/ou descascamento, dificultando o processo de higienização das instalações e dos móveis em tais áreas. Costa et al. (2013) também observaram que $85,71 \%$ $(n=17)$ das áreas de manipulação de carne in natura não estavam visualmente limpas, apresentando sujidades e sangue. Da mesma maneira Soto et al. (2006), pesquisando as condições sanitárias de quatro supermercados do município de lbiúna (SP), verificaram que os procedimentos de limpeza e desinfecção do local eram feitos de forma inadequada.

A RDC no 216/2004 (BRASIL, 2004) preconiza que as instalações, os equipamentos, móveis e utensílios devem ser mantidos em condições higiênico-sanitárias apropriadas $e$ as operações de higienização e sanitização realizadas com frequência e por funcionários

comprovadamente capacitados, garantindo a manutenção dessas condições e minimizando o risco de contaminação aos alimentos.

Ainda em relação à higiene das instalações, a presença de objetos em desuso nas áreas de manipulação de alimentos pode servir de abrigo para vetores e pragas urbanas, além de favorecer o acúmulo de pó e sujidades. Todavia, notou-se a presença de tais objetos em $42,11 \%(n=8)$ dos açougues; $52,63 \%(n=10)$ das padarias/rotisserias e $84,21 \% \quad(n=16)$ dos estoques secos avaliados. Da mesma maneira, Vidal et al. (2011) observaram a presença de equipamentos em desuso na área interna de uma UAN localizada na cidade de Belém do Pará, dificultando o Manejo Integrado de Pragas (MIP), a limpeza e a desinfecção.

No que concerne ao armazenamento de produtos no estoque seco, observou-se que $73,68 \% \quad(n=14)$ dos supermercados apresentavam alimentos armazenados desorganizadamente, em local sujo, com presença ou vestígios de pragas, entulhos e/ou materiais tóxicos; além disso, $63,16 \% \quad(n=12) \quad$ possuíam produtos alimentícios armazenados em contato direto com o piso, deixando os alimentos suscetíveis à contaminação e dificultando o processo de higienização no local.

O controle de temperatura é uma das principais ferramentas no controle do crescimento microbiano e, quando realizado inadequadamente, pode tornar-se uma das causas mais frequentes da multiplicação de microrganismos e da deterioração dos alimentos (Cardoso et al., 2011; Silveira et al., 2015; Adams e Moss, 2008). De acordo com Vidal et al. (2011), o monitoramento do binômio tempo e temperatura é essencial, visto que evita altas contagens de microrganismos nos alimentos e garante a qualidade do 
produto final. Todavia, com relação ao controle de temperatura da rede de frios, contatou-se que $94,74 \% \quad(n=18)$ dos estabelecimentos avaliados não apresentavam planilhas preenchidas e não realizavam 0 controle de temperatura de equipamentos de refrigeração/congelamento, sendo possível observar que $47,37 \%(n=9)$ das ilhas de produtos congelados e 15,79\% $(n=3)$ das câmaras frias de produtos cárneos congelados e dos freezers dos açougues não estavam regulados para manter a temperatura de $18^{\circ} \mathrm{C}$ negativos, conforme o preconizado na legislação sanitária vigente (BRASIL, 2004). Além disso, $26,32 \%(n=5)$ das ilhas encontravam-se com produtos armazenados acima da linha de carga fixada pelo fabricante do equipamento, impedindo a manutenção da temperatura adequada e apresentando produtos com sinais de descongelamento. Resultados semelhantes foram obtidos por Silveira et al. (2015) em inspeções realizadas em 24 serviços de alimentação da cidade de Itaqui (RS), nas quais foi possível verificar ausência do controle de temperatura da rede de frio de $60 \%$ $(n=14)$ dos estabelecimentos em perquirição. Vidal et al. (2011) também constataram que não haviam planilhas de registro da temperatura tampouco comprovantes de manutenção preventiva dos equipamentos e maquinários da UAN avaliada, uma vez que se aplicava somente a manutenção corretiva.

Durante o acompanhamento do recebimento de mercadorias nos estabelecimentos avaliados, foi possível verificar que os procedimentos de inspeção recomendados não eram realizados. A ANVISA (BRASIL, 2004) estabelece que a recepção de mercadorias deve ser realizada em área protegida e limpa, sendo os produtos submetidos à inspeção para a mensuração da temperatura de alimentos perecíveis e a avaliação da integridade das embalagens, das características sensoriais, do número dos lotes e dos prazos de validade. Para mais, informações importantes como o registro nos serviços de inspeção também devem ser verificadas em produtos de origem animal. No entanto, as temperaturas de produtos da rede de frios não eram mensuradas e anotadas em planilhas de controle as temperaturas em $89,47 \% \quad(n=17)$ dos estabelecimentos, além disso, em $52,63 \% \quad(n=10)$ dos casos não eram averiguadas as datas de validade das mercadorias, os números dos lotes, os registros nos serviços de inspeção, as características sensoriais, a integridade das embalagens e o estado de higiene dos produtos. Com relação a área de recebimento de mercadorias, 78,95\% $(n=15)$ não eram protegidas contra chuva, sol e/ou poeira e apresentavam objetos em desuso e/ou presença de animais; e $84,21 \% \quad(n=16)$ não eram mantidas em condições higiênico sanitárias apropriadas.

Estes resultados corroboram com resultados obtidos por Santos et al. (2010), que, ao avaliarem a adequação às Boas Práticas em cinco restaurantes do município do Rio de Janeiro, puderam notar que nenhum (100\%) dos estabelecimentos apresentavam controle de temperatura na recepção de mercadorias perecíveis e apenas um realizava este procedimento em local protegido e limpo. Do mesmo modo, Rodrigues e Martins (2008) notaram a ausência da verificação da higiene das matérias-primas, das temperaturas, das características sensoriais, da integridade das embalagens, das condições de transporte e da higiene do fornecedor, na recepção dos alimentos. O descumprimento dos procedimentos de inspeção de mercadorias pode ameaçar a inocuidade dos alimentos, possibilitando a comercialização e/ou 
utilização de produtos impróprios para o consumo.

No que tange às Boas Práticas inerentes ao asseio pessoal dos manipuladores de alimentos, a ANVISA (BRASIL, 2004) determina que os mesmos apresentem-se asseados; com uniformes completos, fechados, em cores claras, bem conservados e limpos; cabelos presos e protegidos por redes, toucas ou bonés; unhas curtas e sem esmalte ou base; sem barba ou bigode; sem maquiagem; e sem adornos pessoais. Além de que, uniformes completos e calçados com solados antiderrapantes constituem importantes Equipamentos de Proteção Individual (EPI) para evitar acidentes de trabalho. Entretanto, observou-se que os manipuladores de alimentos não encontravam-se vestindo uniformes em $36,84 \% \quad(n=7)$ dos estabelecimentos, tampouco utilizavam calçados fechados e antiderrapantes em $31,58 \%(n=6)$ dos supermercados, sendo possível visualizá-los, em alguns casos, calçando chinelos. Em relação ao uso de adornos pessoais e barba ou bigode, foi possível notar a utilização dos mesmos por funcionários de 78,95\% (n=15) e $36,84 \% \quad(n=7)$ dos estabelecimentos, respectivamente. Guimarães e Figueiredo (2010), ao analisarem as condições higiênico-sanitárias de três panificadoras localizadas no município de Santa Maria do Pará (PA), concluíram que os manipuladores não tinham 0 hábito de usar uniformes completos e EPI, estando fora dos padrões estabelecidos pela legislação. Além disso, estes autores também verificaram que algumas manipuladoras utilizavam adornos, como relógio, pulseira e brincos, durante o expediente de trabalho.

De acordo com Gomes (2011), "os uniformes podem representar fonte de contaminação dos alimentos, sendo obrigatório aos manipuladores apresentar-se com uniformes compatíveis com as suas funções, em bom estado de conservação e limpeza". A não utilização do uniforme completo $\mathrm{e}$ de calçados fechados pode suscitar acidentes de trabalho assim como colocar em risco a produção de alimentos seguros. Além disso, barba e adornos pessoais podem ser fontes de microrganismos, possibilitando a transferência de patógenos para os alimentos manipulados.

Quanto ao controle de vetores e pragas urbanas, a presença e/ou vestígios dos mesmos foi constatada em $63,16 \%(n=12)$ dos casos, apesar da maioria ( $n=12)$ dos supermercados contar com comprovante de desratização e desinsetização realizado por empresa terceirizada credenciada nos órgãos de vigilância sanitária. Tal fato evidencia a importância da adesão às medidas do Manejo Integrado de Pragas (MIP), uma vez que a aplicação de produtos químicos, por si só, não apresenta alta resolubilidade no controle destes animais. Segundo a ANVISA, o MIP é um "sistema que incorpora ações preventivas e corretivas destinadas a impedir a atração, o abrigo, o acesso e ou a proliferação de vetores e pragas urbanas" (BRASIL, 2004).

O controle de pragas em ambientes de manipulação requer uma análise criteriosa das instalações físicas e das condições de higienização, armazenamento e entrada de mercadorias no local, sendo assim, serviços de alimentação devem instaurar medidas preventivas como: ralos com sistema de fechamento e/ou sifonados, telas milimétricas em todas as aberturas externas, portas com sistema de fechamento automático e borracha de vedação na parte inferior, cortinas de ar, evitar o acúmulo de lixo nas áreas interna e externa do estabelecimento, manter as áreas de manipulação em condições de higiene 
adequadas e sem objetos em desuso, dentre outras. Entretanto, em sua maioria, os estabelecimentos analisados não apresentavam as medidas estruturais e organizacionais supracitadas, favorecendo a atração, o acesso, a proliferação e o abrigo de vetores e pragas em áreas internas.

Para mais, recentemente foi instituída pela Secretaria Estadual de Saúde do Paraná a Resolução SESA n 374/2015, que também responsabiliza as empresas terceirizadas pelo MIP, devendo as mesmas apresentarem 0 comprovante de prestação de serviço, o mapeamento das iscas e armadilhas e o relatório de inspeção. Este último, deve conter data e assinatura do responsável técnico, indícios de infestação, presença de abrigo e aberturas, medidas preventivas a serem adotadas pelo contratante, controle de eficiência das iscas e inspeção das armadilhas. Além disso, a resolução estabelece que o controle de pragas deve ser priorizado por meio de ações multidisciplinares, evitando o uso excessivo de produtos químicos, otimizando o uso de barreiras físicas e mecânicas e ações educativas (PARANÁ, 2015).

A presença de pragas pode estar relacionada à falta de conhecimento sobre a prevenção e à ausência de um programa de Boas Práticas direcionadas ao controle destes animais, tornando-se imprescindível a capacitação profissional e a adoção de medidas preventivas (Brasil, 2011).

Por fim, ao avaliar os comprovantes de capacitação dos manipuladores em Boas Práticas higiênicas, foi possível notar que $84,21 \%(n=16)$ dos supermercados não apresentavam comprovantes de treinamento dos funcionários, tampouco responsabilidade técnica exercida por profissional legalmente habilitado para capacitá-los. O responsável técnico configura 0 elo entre a vigilância sanitária (VISA) e o setor regulado, tornando-se de extrema importância para a garantia da adesão às Boas Práticas higiênicas nos estabelecimentos. A falta deste profissional pode acarretar a não qualificação dos manipuladores, em relação às Boas Práticas, para 0 desenvolvimento de suas atividades e, consequentemente, a possível oferta de alimentos não inócuos motivada pela inexistência de conhecimento.

Além disso, as ações da VISA, muitas vezes, podem explicitar 0 importante poder de polícia sob estabelecimentos cujas atividades tenham relação com a saúde pública, com intervenções que podem assumir um caráter repressivo. Contudo, a vigilância não reduz-se apenas à dimensão do vigiar e punir. Ainda em relação ao treinamento dos funcionários, embora na atuação do serviço de vigilância predomine 0 exercício do controle, o papel da VISA deve articular diversos atores sociais em uma construção conjunta do saber, visando a promoção da saúde por meio do conhecimento e da participação ativa de todos os envolvidos (Chagas e Villela, 2014). A educação, com a responsabilização e a participação integrada, pode produzir impacto no cotidiano operacional. Dessa forma, o processo formativo, embasado em metodologias ativas de educação, pode consolidar o conhecimento, promovendo o fortalecimento de determinadas práticas higiênicas nos supermercados.

\section{CONCLUSÕES}

Diante do exposto, conclui-se que - panorama higiênico-sanitário encontrado nos supermercados visitados foi insatisfatório, evidenciando ausência de conformidade em pontos críticos para a segurança alimentar, como: risco de contaminação cruzada, inexistência do controle de temperatura na rede de frio, carência asseio e 
higiene pessoal dos manipuladores de alimentos, ausência do manejo integrado de pragas, armazenamento inadequado dos alimentos e omissão da documentação prescrita na legislação sanitária vigente, podendo colocar em risco a saúde do consumidor.

Para mais, estudos que realizam o levantamento das Boas Práticas higiênicas por meio da padronização de listas de verificação, semelhantes a este, seguem muito além da ação fiscalizadora, servindo de subsídio para as ações educativas da VISA e gerando a possibilidade de uma construção conjunta de conhecimento direcionado para a realidade local. Dessa forma, tais pesquisas podem gerar uma aproximação entre o serviço público de vigilância em saúde e o setor regulado, acarretando maior responsabilidade de todos os atores envolvidos e auxiliando na promoção da saúde pública.

\section{Agradecimento}

Os autores agradecem aos servidores do Departamento de Vigilância Sanitária de Alimentos do município de realização da pesquisa e aos responsáveis pelos supermercados pela permissão para a coleta de dados.

\section{Notas informativas}

O presente estudo foi aprovado no Comitê de Ética e Pesquisa (CEP) da Universidade Tecnológica Federal do Paraná, sob no do CAAE 57206416.2.0000.5547 e intitulado "Promoção de boas práticas higiênicas em supermercados, mercados e restaurantes na região metropolitana de Curitiba".

\section{REFERÊNCIAS}

ADAMS, M. R.; MOSS, M. O. Food Microbiology. 3rd ed. Cambridge: The Royal Society of Chemistry. 2008.
AZEVEDO, M. F. O marketing varejista e sua preocupação de atender melhor. Revista Eletrônica Temática, 2007. Disponível em: $<w w w$.insite.pr.br/2007/38.pdf>. Acesso em: 15/12/2017.

BRASIL, Agência Nacional de Vigilância Sanitária. Resolução RDC n. 275, de 21 de outubro de 2002. Regulamento técnico de Procedimentos Operacionais Padronizados e a lista de verificação de Boas Práticas de fabricação em estabelecimentos

produtores/industrializadores de alimentos. Diário Oficial da União. 23 de outubro de 2002.

BRASIL, Agência Nacional de Vigilância Sanitária. Resolução RDC n. 216, de 15 de setembro de 2004. Regulamento técnico de Boas Práticas para serviços de alimentação. Diário Oficial da União. 16 de setembro de 2004.

BRASIL, C. C. B. Diagnóstico do perfil dos estabelecimentos do setor supermercadista de acordo com a legislação de alimentos. 2011. Santa Maria, 138 f. Dissertação de Mestrado Curso de Pós-Graduação em Ciência e Tecnologia dos Alimentos. Universidade Federal de Santa Maria. Centro de Ciências Rurais.

CARDOSO, M.F.; MIGUEL, V.; PEREIRA, C.A.M. Avaliação das condições higiênico-sanitárias e de boas práticas de fabricação em panificadoras. Alimentos e nutrição Araraquara. v. 22, n. 2, p. 211-217, abr./jun. 2011.

CHAGAS, M.F.; VILLELA, W.V. Vigilância Sanitária e promoção de saúde: apontamentos para além da regulação e controle. Revista VISA em debate. v.2, n. 3, p. 30-36, 2014.

CNAE - Classificação Nacional de Atividades Econômicas. Ministério do Planejamento, Orçamento e Gestão. Comissão Nacional de Classificação 
e Instituto Brasileiro de Geografia, versão 2.0. Rio de Janeiro, 2007.

Codex Alimentarius. CAC/RCP 39 de 1993. Code of Hygienic Practice for Precooked and Cooked Foods in Mass Catering. Disponível em: $<$ http://www.codexalimentarius.net/web/ standard list.jsp>. Acesso em: 14/12/2017.

COSTA, T.S.; NEIVA, G.S.; CAMILO, V.M.A.; et al. Oficinas de boas práticas de fabricação: construindo estratégias para garantir a segurança alimentar. Brazilian Journal of Food Technology. IV SSA, p. 64-68, maio, 2012

COSTA, J.N.P.; SANTOS, V.V.M.; SILVA, G.R.; et al. Condições higiênicosanitárias e físico-estruturais da área de manipulação de carne in natura em minimercados de Recife (PE), Brasil. Arquivos do Instituto Biológico, São Paulo, v.80, n.3, p. 352-358, 2013.

FARIA, D. B. Contaminação cruzada durante 0 fatiamento de produto cárneo pronto para o consumo: foco em Listeria monocytogenes.2016. São Paulo. 62f. Dissertação de Mestrado em Ciência dos Alimentos. Área de Bromatologia. Universidade de São Paulo. Faculdade de Ciências Farmacêuticas.

FORSYTHE, S. J. Microbiologia da segurança dos alimentos. 2. Ed. Porto Alegre: Artmed, 2013.

GOMES, J.C. Legislação de alimentos e bebidas. Viçosa: UFV, 2007. 635p.

GOMES, M.F.F.A. Unidades produtoras de refeições dos meio de hospedagem de Maceió: avaliação dos requisitos de Boas Práticas na manipulação de alimentos. 2011. Maceió. 122f. Dissertação de Mestrado em Nutrição. Universidade Federal de Alagoas. Faculdade de nutrição.

GUIMARÃES, S.L.; FIGUEIREDO, E.L. Avaliação das condições higiênico- sanitárias de panificadoras localizadas no município de Santa Maria do ParáPA. Revista Brasileira de Tecnologia Agroindustrial. v. 04, n. 02: p.198-206, 2010.

LEITE, L.H.M.; MACHADO, P.A.N.; VASCONCELLOS, A.L.R.; et al. Boas práticas de higiene e conservação de alimentos em cozinhas residenciais de usuários do programa saúde da famíliaLapa. Revista de Ciências Médicas, Campinas, v.18, n.2, p.81-88, mar./abr., 2009

MEIRELES, S.V. Avaliação da qualidade de carne de sol comercializada no município de Palmas - TO. 2015. Palmas, TO. 36f. Dissertação de conclusão de curso em Ciências Farmacêuticas do curso de Farmácia. Centro Universitário Luterano de Palmas.

MELLO, J.F.; SCHNEIDER, S.; LIMA, M.S.; et al. Avaliação das condições de higiene e da adequação às boas práticas em unidades de alimentação e nutrição no município de Porto Alegre RS. Alimentos e nutrição Araraquara. v. 24, n.2, p. 175-182, abr./jun. 2013.

OMS. Estrategia global de la OMS para la inocuidad de los alimentos: alimentos más sanos para una salud mejor. Disponível em: $<$ http://apps.who.int/iris/bitstream/10665/ 42705/1/9243545744.pdf> Acesso em: 24/01/2018.

PARANÁ. Resolução SESA $\mathbf{n}^{\circ}$ 374/2015. Dispõe sobre Norma Técnica para funcionamento de empresas especializadas na prestação de serviço de controle de vetores e pragas urbanas e dá outras providências. 30 set 2015.

RAMOS, M. B. Segurança alimentar no contexto da vigilância sanitária: reflexões e práticas. Rio de Janeiro: Escola Politécnica de Saúde Joaquim Venâncio, 2014. 
RODRIGUES, S.; MARTINS, A. H. Avaliação da estrutura física em unidades de alimentação e nutrição da cidade de Cascavel, Paraná. 2008. 13 f. Monografia. Centro Universitário FAG, Cascavel.

SANTOS, M.O.B.; RANGEL, V.P.; AZEREDO, D.P. Adequação de restaurantes comerciais às boas práticas. Revista Higiene Alimentar. v.24, n.190/191, p. 44-49, nov/dez. 2010.

SILVA JR., E. A. Manual de controle higiênico-sanitário em serviços de alimentação. São Paulo: Varela. 2005.

SILVEIRA, J.T.; BRASIL, C.C.B.; FLORIANO, J.M.; et al. Condições higiênicas e boas práticas de manipulação em serviços de alimentação da cidade de Itaqui-RS. Revista VISA em debate. v.3, n.2, p.144-149, 2015.

SOTO, F. R. M.; RISSETO, M. R.; CAZZOLA, C. P. B.; et al. Proposta e análise crítica de um protocolo de inspeção e de condições sanitárias em supermercados do município de Ibiúna SP. Revista Brasileira de Epidemiologia, São Paulo, v.9, n.2, p.235-241, 2006.

SOUZA, L. H. L. A manipulação inadequada dos alimentos: fator de contaminação. Revista Higiene Alimentar. São Paulo, v.20, n.146, p.32-39, 2006.

VIDAL, G.M.; BALTAZAR, L.R.S; COSTA, L.C.F.; et al. Avaliação das boas práticas em segurança alimentar de uma unidade de alimentação e nutrição de uma organização militar da cidade de Belém, Pará. Alimentos e nutrição Araraquara. v. 22, n. 2, p. 283-290, abr./jun. 2011.

WHO. World Health Organization. Foodborne disease. Disponível em: <http://www.who.int/topics/foodborne di seases/en/>. Acesso em: 15/12/2017. 